
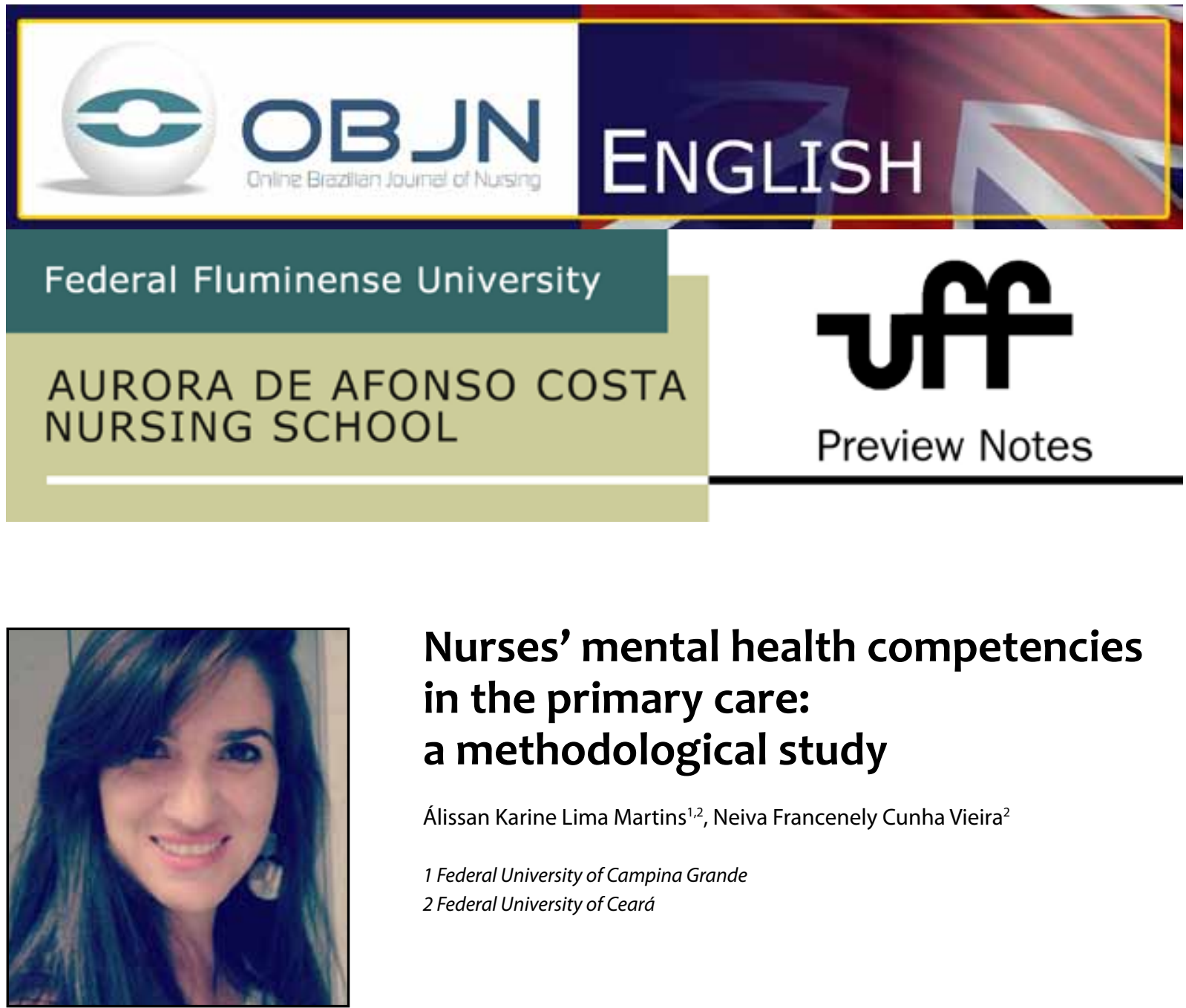

\title{
Nurses' mental health competencies in the primary care: a methodological study
}

\author{
Álissan Karine Lima Martins ${ }^{1,2}$, Neiva Francenely Cunha Vieira ${ }^{2}$ \\ 1 Federal University of Campina Grande \\ 2 Federal University of Ceará
}

\section{ABSTRACT}

Aim: To develop a competence scale for nurses' work in terms of mental health in Primary Health Care (PHC). Method: This is a methodological piece of research, in which a quantitative approach will be performed in two steps: 1) the construction and content validation of a scale of competencies for nursing work in terms of mental health in the PHC and; 2) the application of the instrument to the nurses of the Family Health Strategy units of municipalities of the $20^{\text {th }}$ and $21^{\text {st }}$ Health Regional Coordination Department of Ceará. Data will be analysed by comparing averages, by means of Student's $t$ tests and Snedecor F, and by association and correlations analysis of skills compared with the characteristics of nurses. The standards of Resolution $466 / 2012$, which regulate research involving human subjects, will be adhered to.

Descriptors: Mental Health; Primary Health Care; Nursing; Validation Studies. 


\section{PROBLEM SITUATION AND ITS SIGNIFICANCE}

In accordance with public health policies, the practices of mental health care have undergone an intense process of restructuring as part of the Brazilian Psychiatric Reform, which is included in the Primary Health Care (PHC) context $\mathrm{t}^{(1)}$. For the proper operation of the demands on mental health in this new scenario, professionals who are part of the Family Health Strategy (FHS) need to be prepared to adopt behaviors that are grounded in knowledge, skills and attitudes for coping with practical everyday situations with a critical view, incorporating creativity and responsibility.

Even if the skills are recognized, we may highlight the lack of studies addressing the professional role of nurses when it comes to dealing with the demands of mental health ${ }^{(2)}$. Thus, it is necessary for nurses to work in order to build a professional identity as being the ones who are co-responsible for the process of mental health care, so that he is seen as capable of intervening effectively in terms of the demands of mental health to defend the interests of the community in partnership with other health professionals and those in other fields of knowledge.

This study aims to contribute to the practice of nursing in the FHS, to the incorporation of elements of competence, to guaranteeing the exercise of an activity grounded in knowledge, know-how and know how in such a way as to behave appropriately in the conduct of problem situations in the everyday work of a mental health unit.

\section{AIMS}

To develop a scale of competencies for nursing work in mental health in the PHC; to verify the psychometric properties in terms of the validity and reliability of the scale; to identify the skills in mental health of nurses in the PHC; to verify the existence of an association between such competencies and the socio-demographic variables and professional training of nurses in the PHC.

\section{HYPOTHESIS}

The content of the scale with regard to competencies for nursing in mental health in the PHC will be valid and reliable if the IVC is $\geq$ 0.8 and the Cronbach Alpha is $>0.7$.

\section{METHOD}

This is a methodological piece of research, in which a quantitative approach ${ }^{(3)}$ was chosen. It will involve nurses from basic health units in the municipalities of the $20^{\text {th }}$ and $21^{\text {st }}$ Health Regional Coordination Department of Ceará. The study will consist of two steps: the construction and validation in terms of content of a scale of competencies for nursing in mental health in the PHC and; 2) the application of the instrument to nurses working in FHS units.

The construction of the scale will be based on the document from the National Panel for Psychiatric Mental Health NP Competencies that identifies the skills of nurses working in mental health. The choice and adaptation of the skills listed in the document will be performed according to their applicability to the $\mathrm{PHC}$ environment. With the identification of issues to be incorporated in the instrument, the items that will compose the scale will be organized.

The developed instrument will be submitted to a committee of experts and tested on a pilot group. The validated scale will be applied in 
the nurses' workplace. The reliability of the scale will be verified by the Cronbach Alpha test and the content validity will be verified by the Index of Content Validation (IVC). Descriptive statistical analysis will be used, calculated in terms of percentages related to socio-educational variables, in addition to measures of central tendency such as the average and standard deviation of the scale categories.

Data will be treated by comparing averages by means of Student's t tests and Snedecor F, and by association and correlational analysis of competencies with nurses' characteristics by means of $c^{2}$ nonparametric tests, Fisher and Maximum Likelihood tests. For all inferential statistical analyzes, a significance level of $5 \%$ will be set. Regarding ethical issues, the rules of Resolution 466/2012, which regulate research involving human subjects, will be adhered to. Permission 251.267/2013 was obtained from the Federal University Research Ethics Committee of the University Hospital Alcides Carneiro of the Federal University of Campina Grande.

\section{REFERENCES}

1. Lima Al, Severo AK, Andrade NL, Soares GP, Silva LM. O desafio da construção do cuidado integral em saúde mental no âmbito da atenção primária. Temas Psicol. [internet]; 2013 [Cited 2013 Aug 21]; 21(1):71-82. Available from: http://pepsic. bvsalud.org/pdf/tp/v21n1/v21n1a05.pdf.

2. Neves HG, Lucchese R, Munari DB. Saúde mental na atenção primária: necessária constituição de competências. Rev Bras Enferm. 2010 jul/ago; 63(4):666-70.

3. Lima DVM. Research design: a contribution to the author. Online braz $\mathrm{j}$ nurs [internet]. 2011 Oct [Cited 2013 Aug 26]; 10 (2). Available from: http://www.objnursing.uff.br/index.php/ nursing/article/view/3648. DOI: http://dx.doi. org/10.5935/1676-4285.20113648

All authors participated in the phases of this publication in one or more of the following steps, in According to the recommendations of the International Committee of Medical Journal Editors (ICMJE, 2013): (a) substantial involvement in the planning or preparation of the manuscript or in the collection, analysis or interpretation of data; (b) preparation of the manuscript or conducting critical revision of intellectual content; (c) approval of the versión submitted of this manuscript. All authors declare for the appropriate purposes that the responsibilities related to all aspects of the manuscript submitted to OBJN are yours. They ensure that issues related to the accuracy or integrity of any part of the article were properly investigated and resolved. Therefore, they exempt the OBJN of any participation whatsoever in any imbroglios concerning the content under consideration. All authors declare that they have no conflict of interest of financial or personal nature concerning this manuscript which may influence the writing and/or interpretation of the findings. This statement has been digitally signed by all authors as recommended by the ICMJE, whose model is available in http://www. objnursing.uff.br/normas/DUDE_eng_13-06-2013.pdf

Received: 01/10/2014

Revised: 03/25/2014

Approved: 03/25/2014 